\title{
Türkçeyi Yabancı Dil Olarak Öğrenenlerin Kullandıkları Dil Öğrenme Stratejileri*
}

\section{Language Learning Strategies Used by the Learners of Turkish as a Foreign Language}

\author{
Dilek BAZ BOLLUK **, Hasan BAĞCI ***
}

Öz: Türkçeyi yabancı dil olarak öğrenen öğrencilerin dil öğrenme sürecinde dili daha etkin ve kalıcı bir şekilde öğrenebilmesi için çeşitli dil öğrenme stratejileri mevcuttur. Dil öğrenme stratejileri öğrenenlerin öğrenme sürecini kolaylaştırdığı gibi aynı zamanda bu süreçteki öğrenilenlerin kalıcı olmasını da sağlar. Bu nedenle öğrenenlerin dil öğrenme stratejilerini kullanma düzeylerinin belirlenmesi ve bu konu hakkında bilgilendirilmesi dil öğrenme süreci için önemlidir. Türkçeyi yabancı dil olarak öğrenenlerin kullandıkları dil öğrenme stratejilerinin belirlenmesini ve bu stratejilerin çeşitli değişkenlerle olan ilişkisinin ortaya konulmasını amaçlayan bu araştırmada "betimleyici tarama modeli" kullanılmıştır. Araştırmanın çalışma grubunu 2018-2019 eğitim öğretim yılında çeşitli Yabancılara Türkçe Öğretim Merkezlerinde eğitim öğretim gören B1 ve B2 seviyesindeki 269 öğrenci oluşturmaktadır. Araştırmada Oxford (1990) tarafından geliştirilen Cesur ve Fer (2007) tarafından İngilizceden Türkçeye çevrilen Dil Öğrenme Stratejileri Envanteri ile kişisel bilgi formu kullanılmıştır. Elde edilen veriler Spss 21.000 programında t-testi ve tek yönlü varyans analizi (ANOVA) yardımıyla çözümlenmiştir. Yapılan analiz sonucunda Türkçeyi yabancı dil olarak öğrenenlerin dil öğrenme stratejilerini kullanma sıklı̆ının yüksek seviyede olduğu ve öğrenenlerin en fazla üstbilişsel ve sosyal stratejileri, en az da hafiza stratejilerini kullandığı belirlenmiştir. Araştırmanın bir başka alt problemi olan Türk televizyon kanallarını izleme değişkeninde de istatistiki olarak anlamlılık olduğu sonucuna ulaşılmıştır.

Anahtar Kelimeler: Dil öğrenme stratejileri, Türkçeyi yabancı dil olarak öğrenenlerin kullandıkları dil öğrenme stratejileri, yabanc1lara Türkçe öğretimi

\begin{abstract}
There are several language learning strategies available for students who learn Turkish as a foreign language to learn the language more effectively and permanently during the language learning process. Language learning strategies facilitate the learning process of learners as well as ensure that the learning process is permanent. It is therefore important for the language learning process to determine the level of learners to use language learning strategies and to inform them about this topic. Turkish as a foreign language learners language learning strategies and they use these strategies this study which aims to reveal the relationship between several variables, "in descriptive scanning model" was used. The study group of the study consists of 269 students at B1 and B2 level who are studying at various foreign Turkish teaching centers in the 2018-2019 academic year. In the study, the inventory of Language Learning Strategies, translated from English to Turkish, and the personal data form were used by Bold and Fer (2007), developed by Oxford (1990). The data obtained were analyzed with the help of T-test and one-way variance analysis (Anova) in SPSS 21.000 program. As a result of the analysis, it was determined that those who learned Turkish as a foreign language had a high level of frequency of using language learning strategies and that the learners used the most transcendental and social strategies and the least memory strategies. Another sub-problem of the study, the variable monitoring Turkish television channels, was also statistically significant.
\end{abstract}

Keywords: Language learning strategies, language learning strategies used by learners of Turkish as a foreign language, teaching Turkish to foreigners

\footnotetext{
* Bu makale ikinci yazarın danışmanlığında yürütülen “Türkçeyi Yabancı Dil Olarak Öğrenenlerin Kullandıkları Dil Öğrenme Stratejileri” adlı yüksek lisans tezinden üretilmiştir.

** Mehmet Akif Ersoy Üniversitesi, Eğitim Fakültesi, Burdur-Türkiye, ORCID: 0000-0002-8021-0432, e-posta: bazdilek4@gmail.com

*** Prof. Dr., Mehmet Akif Ersoy Üniversitesi, Eğitim Fakültesi, Burdur-Türkiye, ORCID: 0000-0001-8624-8274, e posta: hbagci@mehmetakif.edu.tr
} 


\section{Giriş}

Dil insanların en temel iletişim aracıdır. Geçmişten günümüze dil ile ilgili birçok tanım yapılmıştır. Dilbilimci Saussure (1985) dilin işaretler ve göstergelerden oluşan bir sistem olduğunu ifade etmiştir. Martinet ise dilin iletişim boyutuna dikkat çekerek "bir dil, insan deneyiminin, topluluktan topluluğa değişen biçemlerde, anlamsal bir içerikle sessel bir anlatımı kapsayan birimlere, başka bir deyişle, anlambirimlere ayrıştırılmasını sağlayan bir bildirişim aracı" olarak tanımlamıştır (Martinet, 1998, 75). Özdemir (2000) ise dili, düşünce, duygu ve dileklerimizi karşımızdakilere anlatmaya yarayan bir işaretler dizgesi olarak tanımlamıştır. Korkmaz (2007) da dili insanlar arasında karşılıklı haberleşme aracı olarak kullanılan duygu, düşünce ve isteklerin ses, şekil ve anlam bakımından her toplumun kendi değer yargılarına göre biçimlenmiş ortak kurallarının yardımı ile başkalarına aktarılmasını sağlayan seslerden örülü, çok yönlü ve gelişmiş sistem şeklinde tanımlamıştır. Benzer bir tanımlama Aksan (1998) tarafından şu şekilde yapılmıştır; "dil, düşünce, duygu ve isteklerin bir toplumda ses ve anlam yönünden ortak olan ögeler ve kurallardan yararlanılarak başkalarına aktarılmasını sağlayan çok yönlü, çok gelişmiş bir dizgedir"(s.11). Dile dair önemli tanımlardan bir tanesi de Ergin (1999) tarafından "dil, insanlar arasında anlaşmayı sağlayan tabiî bir vasıta, kendisine mahsus kanunları olan ve ancak bu kanunlar çerçevesinde gelişen canlı bir varlık, temeli bilinmeyen zamanlarda atılmış bir gizli antlaşmalar sistemi, seslerden örülmüş içtimaî bir müessesedir” (s.3) şeklinde yapılmıştır.

Yapılan tanımlarda dilin daha çok iletişim işlevi üzerinde durulduğu görülmektedir. Öyle ki insanlar dil aracıllğıyla diğer toplumlarla iletişim kurabilmekte hatta kurulan iletişim sayesinde toplumlar gelişebilmektedir. Gelişen teknoloji ve ihtiyaçlar doğrultusunda toplumların birbirleriyle iletişim kurma gerekliliği her geçen gün artmaktadır. $\mathrm{Bu}$ durum yabancı dil öğrenmenin gerekliliğini ortaya koymuştur.

Ozil (1991) yabancı dil bilmenin gerekliliğini yabancı bir dil ya da diller, bize bu dillerin dünyayı algılama biçimlerini ve değer sistemlerini tanıttığından, hem o dillerin kültürleriyle donanmış kişilerle her alanda daha iyi iletişim kurabilmemizi sağlıyor, hem de kendi düşüncemizi geliştiriyor, bunun da ötesinde kültürler arasında değişik ve aynı olan yanlar kendi varlığımızın, kendi benliğimizin bilincine daha iyi varmamıza ve kendi konumumuzu daha iyi belirlememize yardımcı oluyor sözleriyle açıklamıştır.

Bir yabanc1 dil bilmenin ayrıcalık olmaktan çıkıp, herkesin sahip olması gereken bir nitelik olduğu günümüzde buna paralel olarak yabancı dil bilmenin önemi de artmıştır (Göçer, 2009). Yabancı dil bilmenin öneminin artmasıyla birlikte insanlar ana dilleri dışında yeni diller öğrenmeye yönelmişlerdir. Türkçe de diğer diller gibi insanların yabancı dil olarak öğrenmek istediği diller arasında yer almaktadır. Bu duruma paralel olarak da Türkçenin yabancı dil olarak öğretimine verilen önem gün geçtikçe artmaktadır. Kızılaslan'a (2010) göre toplumlar arası iletişimin doğru ve etkin bir biçimde sağlanabilmesi için, dil bilgisel doğruluktan daha çok kültürel yöne odaklanan ve kültürler arası farklılıklara hoşgörü ile bakabilen yabanc1 dil konuşucularına ihtiyaç duyulmaktadır.

Türkçenin yabancı dil olarak öğretiminin önem kazanması yabancılara Türkçe öğretimi alanıyla ilgili yapılan çalışmaların sayısının da artmasını sağlamaktadır. Yapılan çalışmalar doğrultusunda öğrenenlerin dil öğrenme sürecini etkileyen birçok faktör araştırılmış ve bireysel farklı1ıkların dil öğrenme sürecini etkilediği görülmüsştür. "Bireylerin öğrenmesini etkileyen bu bireysel farklılıklar zekâ, yetenek türü, öğrenme stili, öğrenme stratejileri, ön bilgi düzeyi, kişilik yapısı, ilgileri, güdülenme tür ve düzeyi, cinsiyet, yaş vb. özellikler olarak sıralanmaktadır "(Smith ve Ragan, 1999, s. 55).

Alan yazın tarandığında Türkçeyi yabancı dil olarak öğrenen öğrencilerin kullandıkları dil öğrenme stratejileri üzerine çok fazla çalışma (Barut, 2015; Boylu,2015; Bölükbaş, 2013; Ergin,2018; Göçer,2017; Yalçın, 2018; Varışoğlu,2018) yapılmadığı görülmektedir. Dil öğrenme süreci için oldukça önemli olan bu konu üzerine yeterince çalışma yapılmaması alanyazında çok önemli bir boşluğun olduğunu göstermektedir. Buna ek olarak Türkçeyi yabancı dil olarak öğrenmek isteyen öğrencilerin kullandıkları dil öğrenme stratejilerinin tespit edilmesinin dil öğrenme sürecini olumlu yönde etkileyeceği de düşünülmektedir. Yapılan çalışmalar ise bu düşünceyi Türkçeyi yabancı dil olarak öğrenen öğrencilerin dil öğrenme stratejileri ile yabancı 
dili iyi öğrenmek arasında doğrudan bir ilişkinin olduğunun belirlenmesi yönüyle destekler niteliktedir (Altan, 2003; Bekleyen, 2006; Nisbet, Tindall ve Arroyo, 2005). Bu bağlamda yapılan çalışmanın Türkçeyi yabancı dil olarak öğrenenlerin kullandıkları dil öğrenme stratejilerinin belirlenmesi ve çeşitli değiş̧kenlerle karşılaştırılmasını ortaya koyması yönüyle önemli olduğu düşünülmektedir.

\section{Araştırmanın amacı}

Yabancılara Türkçe öğretimi alanında yapılan bu araştırma Türkçeyi yabancı dil olarak öğrenenlerin kullandıkları dil öğrenme stratejilerini ve öğrenenlerin kullandığı dil öğrenme stratejilerinin bazı değişkenlere göre değişip değişmediğini belirlemeyi amaçlamaktadır.

\section{Problem cümlesi}

Yapılan bu araştırmanın temel problemi, Türkçeyi yabancı dil olarak öğrenenlerin kullandıkları dil öğrenme stratejileri nelerdir? şeklinde belirlenmiştir.

\section{Alt problemler}

$\mathrm{Bu}$ araştırmada temel alt probleme ek olarak aşağıdaki alt problemlere de cevaplar aranmıştır.

1. Türkçeyi yabancı dil olarak öğrenenlerin kullandıkları dil öğrenme stratejileri hangi düzeydedir?

2. Türkçeyi yabancı dil olarak öğrenenlerin kullandıkları dil öğrenme stratejileriyle cinsiyet değişkeni arasında bir ilişki var mıdır?

3. Türkçeyi yabancı dil olarak öğrenenlerin kullandıkları dil öğrenme stratejileriyle Türk televizyon kanallarını izleme değişkeni arasında bir ilişki var mıdır?

4. Türkçeyi yabancı dil olarak öğrenenlerin kullandıkları dil öğrenme stratejileriyle ana dili alfabesi arasında bir ilişki var mıdır?

\section{Yöntem}

Bu bölümde araştırmanın modeli, araştırmanın evren ve örneklemi, veri toplama araçları, verilerin toplanması ve verilerin analizi başlıklarına yer verilmiştir.

\section{Araştırma modeli}

Tarama modeli geçmişte ya da hâlen var olan bir durumu var olduğu şekliyle ortaya koymayı amaçlayan araştırma yaklaşımıdır (Karasar, 2012, s. 77). Bu tür çalışmalarda daha çok olayın veya problemin mevcut durumu nedir ve neredeyiz sorularına cevap aranmaktadır (Çepni, 2007). Türkçeyi yabancı dil olarak öğrenenlerin kullandıkları dil öğrenme stratejilerinin tespit edilmesi ve bu stratejilerin çeşitli değişkenlerle olan ilişkisinin ortaya konulmasını amaçlayan bu araştırmada "betimleyici tarama modeli" kullanılmıştır.

\section{Araştırmanın evren ve örneklemi}

Araştırmanın evrenini 2018-2019 yılında Yabancılara Türkçe Öğretimi Merkezlerinde eğitim gören öğrenciler oluşturmaktadır. Örneklemi ise Burdur Mehmet Akif Ersoy Üniversitesi, Süleyman Demirel Üniversitesi, Akdeniz Üniversitesi, Eskişehir Osman Gazi Üniversitesi, Gazi Üniversitesi ve İnönü Üniversitesi Yabancılara Türkçe Öğretim Merkezlerinde eğitim öğretim gören B1 ve B2 seviyesindeki 269 öğrenci oluşturmaktadır. Araştırmada kullanılan ölç̧eğin maddelerinin örneklem grubu tarafından daha iyi kavranabilmesi için özellikle orta seviye yani B1 ve B2 seviyesindeki öğrenciler seçilmiştir. 
Tablo 1.

Araştırmaya Katılan Öğrencilerin Cinsiyete Göre Dağılımları

\begin{tabular}{lll}
\hline Cinsiyet & F & $\%$ \\
\hline Erkek & 132 & 49.07 \\
Kiz & 137 & 50.93 \\
Toplam & 269 & 100 \\
\hline
\end{tabular}

Araştırmaya katılan öğrencilerin cinsiyet bilgilerinin yer aldığı Tablo 1'e bakıldığında öğrencilerin 132'sinin erkek 137'sinin de kı olduğu görülmektedir. Bu verilerden hareketle araştırmaya katılan erkek öğrenciler ile kız öğrenciler arasında sayısal olarak önemli bir farkın olmadığı söylenebilir.

Tablo 2.

Araştırmaya Katılan Öğrencilerin Ana Dili Alfabelerine Göre Dağılımları

\begin{tabular}{lll}
\hline Ana Dil & $\mathrm{f}$ & $\%$ \\
\hline Latin & 51 & 18.96 \\
Arap & 110 & 40.89 \\
Diğer & 108 & 40.15 \\
Toplam & 269 & 100 \\
\hline
\end{tabular}

Tablo 2'de araştırmaya katılan öğrencilerin kullandıkları ana dili alfabeleri Latin, Arap ve Diğer şeklinde gruplandırılmıştır. Öğrencilerin kişisel bilgi formuna verdikleri cevaplar incelenirken bazı alfabelerin (Kril, Çin vb.) istatistiki olarak yeterli sayıya ulaşamamasından dolayı "Diğer" şeklinde bir gruplama yapılmıștır. Yukarıda verilen tablo incelendiğinde ise araştırmaya katılan öğrencilerin ana dili alfabelerinin 110'unun Arap, 51'nin Latin alfabesi ve 108 'nin de Diğer alfabeleri kullandıkları görülmektedir.

\section{Veri toplama araçları}

$\mathrm{Bu}$ araştırmada Türkçeyi yabancı dil olarak öğrenen öğrencilerin kullandıkları dil öğrenme stratejilerini belirlemek için "Dil Öğrenme Stratejileri Envanteri" ve kişisel bilgi formu kullanılmıştır.

Dil Öğrenme Stratejileri Envanteri (DÖSE): Elli maddelik DÖSE Oxford (1990, s.293) tarafından yabancı dil olarak İngilizce öğrenenler için hazırlanmıştır. Dil Öğrenme Stratejileri Envanterinin iki temel boyut ve altı alt boyutu bulunmaktadır. Envanterin tümünden alınan puan yoktur, çünkü bir temel boyut, altında yer alan alt ölçeklerde bulunan ve bireyin kullandığı bir dil öğrenme stratejisini diğer boyutlardan bağımsız olarak ölçmektedir. Puanların analizi de alt ölçek bazında yapılmaktadır; bu doğrultuda alt ölçek puanı, alt ölçeğe ait sürekli puanların toplanması ve bu toplamın o alt ölçekteki madde sayısına bölünmesinden elde edilmektedir. Bir alt ölçekten alınabilecek puan ise 1 ile 5 arasında değişmektedir. Her bir birey, en yüksek puan aldığ öğrenme stratejisine atanmaktadır (Cesur, 2008). Ancak bu araştırma esnasında İkinci Düzey Doğrulayıcı Faktör Analizi yapılarak ölçeğin alt boyutlarından elde edilen puanların toplanabilirliği kanıtlanmıştır.

Envanter birçok araştırmada (bkz. Aydın, 2003; Ehrman ve Oxford, 1990; ElDip, 2004; Gan, Humpreys ve Hamp-Lyons, 2004; Hancioglu, 2004; Ian ve Oxford, 2003; Kara, 2001; Karamanoglu, 2005; Lafford, 2004; Mcdonough, 2001; Oxford, Cho, Leung ve Kim, 2004; Tabanlığlu, 2003; Wherton, 2000; Yang, 2003) kullanılmıştır. Envanterin Türkçe formunun geçerlik ve güvenirliği Cesur ve Fer (2007) ile Demirel (2009) tarafından yapılmıştır. Cesur (2008) Envanterin geçerlilik ve güvenirlik çalışmasını yaptıktan sonra doktora tezinde kullanmıştır. Daha sonra Boylu'da (2015) Dil Öğrenme Stratejisi Envanterini bir alan uzmanından yardım alarak tekrar İngilizce‘ den Türkçe‘ ye çevirmiş ve bu Envanteri Yabancılara 
Türkçe Öğretimi alanında kullanılacak hale dönüştürmüştür. Ancak Envanterin orijinal halinin bozulmamasına dikkat edilerek tekrar geçerlilik ve güvenirlik çalışması yapılmıştır.

$\mathrm{Bu}$ araştırmada Oxford (1990) tarafından geliştirilen Cesur ve Fer tarafindan da (2007) İngilizceden Türkçeye çevrilerek, geçerlilik ve güvenirlik çalışması yapılan Dil Öğrenme Stratejileri Envanteri kullanılmıştır. Cesur ve Fer (2007) tarafından çevirinin yapılmış olması ve envanterin İngilizce formuyla Türkçe formu arasında dil eşdeğerliğinin test edilmiş olmasından dolayı tekrar çeviri yapılmamıştır. Araştırmada envanter kullanılmadan önce Cesur ve Fer (2007) tarafindan Türkçeye çevrilen ölçeğin kullanılabilmesi için yazarlardan gerekli olan izinler alınmıştır. Ayrıca hangi seviye grubuna uygulanacağını belirleyebilmek için Mehmet Akif Ersoy Üniversitesi Türkçe Öğretim Merkezinde bulunan 10 öğrenciye en düşük olan A1 seviyesinden başlamak üzere uygulama yapılmış ve yapılan uygulama sonucunda B1 ve B2 seviyesindeki öğrencilerin ölçeği anlamakta güçlük çekmediği ve rahatlıkla soruları cevaplayabildiğ görülmüştür. Bu nedenle ölçeğin araştırmada B1 ve B2 seviyesi öğrencilerine yapılması uygun görülmüştür. Cesur ve Fer (2007) tarafından Türkçeye çevrilen envanterde, beş Türkçe eğitimi alan uzmanının görüşünden faydalanılmış, alan uzmanlarının dönütleri doğrultusunda Türkçeyi yabancı dil olarak öğrenenlerin envanteri daha rahat anlayabilmesi için dil bilgisel bazı düzenlemeler yapılmıştır. Ölçeğin tekrar geçerlilik ve güvenirlik çalışması yapılarak, raporlandırılmıştır.

Kişisel bilgi formu: Araştırmacı tarafından ölçeğin uygulandığ ve dil öğrenme stratejilerinin bazı değişkenlerle ilişkisini belirleyebilmek için 10 maddelik Kişisel Bilgi Formu hazırlanmış ve ölçekle birlikte uygulaması yapılmıştır.

\section{Verilerin toplanması}

Dil Öğrenme Stratejisi Envanteri ile kişisel bilgi formu öğrencilere birlikte uygulanmıştır. Uygulama, merkezlerdeki seviye farklılıklarından dolayı ikinci dönem öğretim yılının 4.hafta ve 12.hafta aralığında bitirilmiştir. Uygulamaların tamamı araştırmacı tarafından yapılarak öğrencilere envanter ile ilgili bilgilendirmeler yapılmıştır. Böylece öğrencilerin envanteri gerçek duygu ve düşüncelerini yansıtacak şekilde cevaplandırabilmeleri sağlanmıştır. Uygulama süresi olarak öğrencilere 30 dakika verilmiştir.

\section{Verilerin analizi}

Yapılan çalışmada veriler SPSS 21.00 ve Lisrell programları aracılığıyla çözümlenmiştir. Dil Öğrenme Stratejileri Envanterinin beşli likert tipinde olmasından dolayı veriler programa olumsuz önermelerden olumlu önermeye artacak şekilde kodlanmıştır. Kişisel bilgi formundaki bulunan 10 madde de SPSS 21.00 programına tanımlanmıştır.

Verilerin tanımlanmasının ardından Türkçeyi yabancı dil olarak öğrenenlerin kullandıkları dil öğrenme stratejileri ve Türkçeyi yabancı dil olarak öğrenenlerin kullandıkları dil öğrenme stratejilerinin cinsiyet, Türkçeyi öğrenme zorluğu algısı, ana dilinin Türkçe öğrenme aşamasında katkı sağlama durumu Türk televizyon kanallarını izleme, Türkiye' de bulunma süresi değişkenlerinde farklılık gösterip göstermediği t-testi yapılarak incelenmiştir. Türkçeyi yabancı dil olarak öğrenenlerin kullandıkları dil öğrenme stratejilerinin ana dili alfabesi, Türkçeyi öğrenme amac1, Türkçe öğrenirken zorlandığını düşündüğü beceri, Türkçe öğrenirken en iyi olduğunu düşündüğü beceri değişkenlerinde farkl1lık gösterip göstermediği ise tek yönlü varyans analizi (ANOVA) yapılarak incelenmiştir.

\section{Bulgular}

\section{Birinci alt probleme ilişkin bulgular}

Araştırmada, "Türkçeyi yabancı dil olarak öğrenenlerin kullandıkları dil öğrenme stratejileri hangi düzeydedir?" olarak ifade edilen birinci alt problemle ilgili elde edilen bulgular aşağıda verilmiştir. 
Tablo 3.

Türkçeyi Yabancı Dil Olarak Öğrenenlerin Kullandıkları Dil Öğrenme

Stratejilerinin Aritmetik Ortalama ve Standart Sapma Değerleri

\begin{tabular}{lll}
\hline Stratejiler & Aritmetik Ortalama & SS \\
\hline Sosyal Stratejiler & 3.62 & .75 \\
Üstbilişsel Stratejiler & 3.61 & .77 \\
Bilişsel Stratejiler & 3.39 & .60 \\
Telafi Edici Stratejiler & 3.39 & .66 \\
Duyuşsal Stratejiler & 3.23 & .71 \\
Hafiza Stratejileri & 3.20 & .63 \\
Toplam Stratejiler & 3.40 & .54 \\
\hline
\end{tabular}

Tablo 3'te Türkçeyi yabancı dil olarak öğrenenlerin kullandıkları dil öğrenme stratejilerinin aritmetik ortalama ve standart sapma değerleri verilmektedir. Verilen değerler incelendiğinde Sosyal Stratejiler $\bar{X}=3.62$; Üstbilişsel Stratejiler $\bar{X}=3.61$; Bilişsel Stratejiler $\bar{X}=3.39$; Telafi Edici Stratejiler $\bar{X}=3.39$; Duyuşsal Stratejiler $\bar{X}=3.23$; Hafiza Stratejileri $\bar{X}=3.20$; Toplam Stratejilerin ise $\bar{X}=3.40$ olduğu görülmektedir. Türkçeyi yabancı dil olarak öğrenenlerin en yüksek oranda $\bar{X}=3.62$ aritmetik ortalama ile "Sosyal Stratejileri" daha sonrada $\bar{X}=3.61$ aritmetik ortalama ile "Üstbilişsel Stratejileri" ve en az $\bar{X}=3.20$ aritmetik ortalamayla da "Hafiza Stratejilerini" kullandıkları tespit edilmiştir. Tablo 3'te verilen aritmetik ortalama değerlerine bakıldığında aritmetik ortalamaların $\bar{X}=3.20$ ile 3.62 arasında değiștiği görülmektedir. Dil öğrenme stratejileri envanterinin alt boyutlarından alınan ortalama puanın 3.00 ile 3.99 arası "sık sık", 2.00 ile 2.99 arası "bazen” kullanma sıklığını göstermektedir (Cesur, 2008). Bu verilerden hareketle Türkçeyi yabancı dil olarak öğrenenlerin kullandıkları dil öğrenme strateji puanlarının 3.00'ın üzerinde olmasından dolayı sik sik dil öğrenme stratejilerinden yararlandıkları söylenebilir.

\section{İkinci alt probleme ilişkin bulgular}

Araştırmada, "Türkçeyi yabancı dil olarak öğrenenlerin kullandıkları dil öğrenme stratejileriyle cinsiyet değişkeni arasında bir ilişki var mıdır?" olarak ifade edilen ikinci alt problemle ilgili elde edilen bulgular aşağıda verilmiştir.

Tablo 4.

Türkçeyi Yabancı Dil Olarak Öğrenenlerin Kullandıkları Dil Öğrenme Stratejilerinin Cinsiyet Değişkenine Göre t-testi Sonuçları

\begin{tabular}{llllllll}
\hline Boyut & Cinsiyet & $\mathrm{N}$ & $\bar{x}$ & $\mathrm{SS}$ & $\mathrm{Sd}$ & $\mathrm{t}$ & $\mathrm{p}$ \\
\hline Hafiza Stratejileri & Kız & 137 & 3.25 & .05 & 267 & 1.49 & .137 \\
& Erkek & 132 & 3.14 & .05 & & & \\
Bilişsel Stratejiler & Kiz & 137 & 3.47 & .05 & 267 & 2.14 & $.033^{*}$ \\
& Erkek & 132 & 3.31 & .05 & & & \\
Telafi Edici Stratejiler & Kiz & 137 & 3.43 & .05 & 267 & 1.19 & .235 \\
& Erkek & 132 & 3.34 & .05 & & & \\
Üstbilişsel Stratejiler & Kiz & 137 & 3.65 & .06 & 267 & .762 & .447 \\
& Erkek & 132 & 3.58 & .07 & & & \\
Duyuşsal Stratejiler & Kız & 137 & 3.17 & .06 & 267 & -1.28 & .199 \\
& Erkek & 132 & 3.29 & .06 & & & \\
Sosyal Stratejiler & Kız & 137 & 3.65 & .06 & 267 & .567 & .571 \\
& Erkek & 132 & 3.60 & .06 & & & \\
Toplam & Kız & 137 & 3.44 & .04 & 267 & 1.23 & .217 \\
& Erkek & 132 & 3.36 & .04 & & & \\
\hline
\end{tabular}

Not. ${ }^{*} \mathrm{p}<0.05 ; \mathrm{N}$ : kişi sayısı; $\overline{\mathrm{X}}$ :ortalama; Ss: standart sapma; sd: serbestlik derecesi; 
Tablo 4'te Türkçeyi yabancı dil olarak öğrenenlerin kullandıkları dil öğrenme stratejilerinin cinsiyet değişkenine göre karşılaştırılması amaciyla bağımsız gruplar t-testi yapılmıştır. Yapılan analiz sonucuna göre ölçeğin alt boyutları dikkate alındığında Türkçeyi yabancı dil olarak öğrenenlerin kullandıkları dil öğrenme stratejilerinin cinsiyet değişkeni açısından incelendiğinde sadece "Bilişsel Stratejiler" boyutunda anlamlı bir fark gösterdiği ortaya çıkmıştır [ $\mathrm{t}(267)=2.14, \mathrm{p}<.05]$. Bu bulguya dayanarak Türkçeyi yabancı dil olarak öğrenen kızların $(\bar{X}=3.47)$ dil öğrenme stratejilerini kullanma seviyeleri Bilişsel Stratejiler alt boyutunda, Türkçeyi yabancı dil olarak öğrenen erkeklere $(\bar{X}=3.31)$ göre daha yüksek olduğu söylenebilir. Ölçeğin diğer alt boyutları olan Hafıza Stratejileri [ $\mathrm{t}(267)=1.49, \mathrm{p}>.05]$, Telafi Edici Stratejiler $[\mathrm{t}(267)=1.19$, $\mathrm{p}>.05]$, Üstbilişsel Stratejiler [ $\mathrm{t}(267)=.762, \mathrm{p}>.05]$, Duyuşsal Stratejiler [ $\mathrm{t}(267)=-1.28, \mathrm{p}>.05]$ ve Sosyal Stratejiler [ $\mathrm{t}(267)=.567, \mathrm{p}>.05]$ boyutlarında ise cinsiyet değişkenine göre anlamlı bir fark oluşmamıştır.

Türkçeyi yabancı dil olarak öğrenenlerin kullandıkları dil öğrenme stratejileri cinsiyet değişkeni açısından ölçeğin bütün boyutlarını oluşturan toplamında da anlamlı farklılık oluşturmadığı görülmüştür [t(267)=1.23, p>.05].

\section{Üçüncü alt probleme ilişkin bulgular}

Araştırmada, "Türkçeyi yabancı dil olarak öğrenenlerin kullandıkları dil öğrenme stratejileriyle Türk televizyon kanallarını izleme değişkeni arasında bir ilişki var mıdır?" olarak ifade edilen üçüncü alt problemle ilgili elde edilen bulgular aşağıda verilmiştir.

Tablo 5 .

Öğrencilerin Türk Televizyon Kanallarını İzleyip İzlememe Durumuna Göre T-Testi Sonuçları

\begin{tabular}{llllllll}
\hline Boyut & TV & $\mathrm{N}$ & $\bar{x}$ & $\mathrm{SS}$ & $\mathrm{df}$ & $\mathrm{t}$ & $\mathrm{p}$ \\
& kanalı & & & & & & \\
\hline Hafiza Stratejileri & Evet & 221 & 3.22 & .63 & 267 & 1.219 & .224 \\
& Hayır & 48 & 3.09 & .66 & & & \\
Bilişsel Stratejiler & Evet & 221 & 3.45 & .61 & 267 & 3.368 & $.001^{*}$ \\
& Hayır & 48 & 3.13 & .50 & & & \\
Telafi Edici Stratejiler & Evet & 221 & 3.41 & .68 & 267 & 1.049 & .295 \\
& Hayır & 48 & 3.29 & .56 & & & \\
Üstbilişssel Stratejiler & Evet & 221 & 3.67 & .78 & 267 & 2.637 & $.009 *$ \\
& Hayır & 48 & 3.35 & .66 & & & \\
Duyuşsal Stratejiler & Evet & 221 & 3.26 & .72 & 267 & 1.534 & .126 \\
& Hayır & 48 & 3.09 & .66 & & & \\
Sosyal Stratejiler & Evet & 221 & 3.65 & .75 & 267 & 1.449 & .148 \\
& Hayır & 48 & 3.48 & .72 & & & \\
Toplam & Evet & 221 & 3.44 & .55 & 267 & 2.617 & $.009 *$ \\
& Hayır & 48 & 3.22 & .47 & & & \\
\hline
\end{tabular}

Not. *p<0.05; N: kişi sayısı; X̃ortalama; Ss: standart sapma; sd: serbestlik derecesi;

Tablo 5'te Türkçeyi yabancı dil olarak öğrenenlerin kullandıkları dil öğrenme stratejileriyle Türk televizyon kanallarını izleme değişkenine göre karşılaştırılması amacıyla bağımsız t-testi yapılmıştır.

Yapılan analiz sonucuna göre ölçeğin alt boyutları incelendiğinde Türkçeyi yabancı dil olarak öğrenenlerin kullandıkları dil öğrenme stratejilerinin Türk televizyon kanallarını izleme değişkeni açısından Bilişsel Stratejiler $[\mathrm{t}(267)=3.368, \mathrm{p}<.05]$ ve Üstbilişsel Stratejiler $[\mathrm{t}(267)=2.637$, $\mathrm{p}<.05$ ] boyutlarında anlamlı bir fark gösterdiği belirlenmiştir. Bu bulgulara dayanarak Bilişsel Stratejiler alt boyutunda, Türkçeyi yabancı dil olarak öğrenenlerden Türk televizyon kanallarını izlediğini ifade edenlerin $(\bar{X}=3.45)$, dil öğrenme stratejilerini kullanma seviyeleri Türk televizyon kanallarını izlemediğini ifade edenlere $(\bar{X}=3.13)$ göre daha olumlu olduğu belirlenmiştir. Yine 
ölçeğin Üstbilişsel Stratejiler alt boyutunda da Türkçeyi yabancı dil olarak öğrenenlerden Türk televizyon kanallarını izlediğini ifade edenlerin $(\bar{X}=3.67)$, dil öğrenme stratejilerini kullanma seviyeleri Türk televizyon kanallarını izlemediğini ifade edenlere $(\bar{X}=3.35)$ göre daha yüksek olduğu belirlenmiştir.

Ölçeğin diğer alt boyutlarına bakıldığında ise Hafıza Stratejileri [t(267)=1.219, p>.05], Telafi Edici Stratejiler [ $\mathrm{t}(267)=1.04, \mathrm{p}>.05]$, Duyuşsal Stratejiler [ $\mathrm{t}(267)=1.53, \mathrm{p}>.05]$ ve Sosyal Stratejiler $[\mathrm{t}(267)=1.44, \mathrm{p}>.05]$ boyutlarında Türk televizyon kanallarını izleme değişkenine göre anlamlı bir fark oluşmamıştır.

Ölçeğin bütününden elde edilen toplam puanına bakıldığında ise Türkçeyi yabancı dil olarak öğrenenlerin kullandıkları dil öğrenme stratejileriyle Türk televizyon kanallarını izleme değişkeni açısından anlamlı fark oluşturduğu görülmüştür $[\mathrm{t}(267)=2.617, \mathrm{p}<.05]$. Yapılan analiz sonuçları incelendiğinde Türkçeyi yabancı dil olarak öğrenenlerden Türk televizyon kanallarını izlediğini belirtenlerin $(\bar{X}=3.44)$, Türk televizyon kanallarını izlemediğini belirtenlere $(\bar{X}=3.22)$ göre dil öğrenme stratejileri puanlarının daha yüksek olduğu belirlenmiştir. Bu sonuçlara bakılarak Türkçeyi yabancı dil olarak öğrenenlerden Türk televizyon kanallarını izlediğini belirtenlerin, Türk televizyon kanallarını izlemediğini belirtenlere göre dil öğrenme stratejilerinin daha yüksek olduğu söylenebilir.

\section{Dördüncü alt probleme ait bulgular}

Araştırmada, "Türkçeyi yabancı dil olarak öğrenenlerin kullandıkları dil öğrenme stratejileriyle ana dili alfabesi arasında bir ilişki var mıdır?" olarak ifade edilen dördüncü alt problemle ilgili elde edilen bulgular aşağıda verilmiş̧tir.

Tablo 6.

Ana Dil Alfabesine Göre ANOVA Sonuçları

\begin{tabular}{|c|c|c|c|c|c|c|c|}
\hline Boyut & & KT & $\mathrm{df}$ & $\mathrm{KO}$ & $\mathrm{F}$ & $\mathrm{P}$ & Anlamlı Fark \\
\hline \multirow{3}{*}{ Hafıza Stratejileri } & Gruplararası & 2.646 & 2 & 1.323 & \multicolumn{2}{|r|}{$\mathrm{D}>\mathrm{L}$} & $\mathrm{A}>\mathrm{L} /$ \\
\hline & Gruplariçi & 106.383 & 266 & .400 & & . & \\
\hline & Toplam & 109.029 & 268 & & & & \\
\hline \multirow{4}{*}{ Bilişsel Strateiler } & Gruplararas1 & .495 & 2 & .247 & .552 & .577 & \\
\hline & Gruplariçi & 119.298 & 266 & .448 & & & \\
\hline & Toplam & 119.793 & 268 & & & & \\
\hline & Gruplararas1 & 1.179 & 2 & .590 & .984 & .375 & \\
\hline \multirow{3}{*}{ Telafi Edici Stratejiler } & Gruplariçi & 159.464 & 266 & .599 & & & \\
\hline & Toplam & 160.643 & 268 & & & & \\
\hline & Gruplararası & .272 & 2 & .136 & .365 & .694 & \\
\hline \multirow[t]{2}{*}{ Üstbilişsel Stratejiler } & Gruplariçi & 99.142 & 266 & .373 & & & \\
\hline & Toplam & 99.414 & 268 & & & & \\
\hline \multirow{4}{*}{ Duyuşsal Stratejiler } & Gruplararası & 2.472 & 2 & 1.236 & 2.418 & .091 & \\
\hline & Gruplariçi & 135.995 & 266 & .511 & & & \\
\hline & Toplam & 138.468 & 268 & & & & \\
\hline & Gruplararası & 3.451 & 2 & 1.726 & 3.078 & $.048 *$ & $A>L / D>L$ \\
\hline \multirow[t]{3}{*}{ Sosyal Stratejiler } & Gruplariçi & 149.137 & 266 & .561 & & & \\
\hline & Toplam & 152.588 & 268 & & & & \\
\hline & Gruplararas1 & .812 & 2 & .406 & .364 & .257 & \\
\hline \multirow[t]{2}{*}{ Toplam } & Gruplariçi & 79.130 & 266 & .297 & & & \\
\hline & Toplam & 79.942 & 268 & & & & \\
\hline
\end{tabular}

$* \mathrm{p}<0.05$

Tablo 6'da Türkçeyi yabancı dil olarak öğrenenlerin kullandıkları dil öğrenme stratejilerinin ana dili alfabe değişkenine göre anlamlı bir farklılık gösterip göstermediği tek yönlü varyans analizi (ANOVA) ile incelenmiştir.

Analiz sonucunda Türkçeyi yabancı dil olarak öğrenenlerin kullandıkları dil öğrenme stratejilerinin ana dili alfabe değişkenine göre ölçeğin Bilişsel Stratejiler $\left[\mathrm{F}_{(2-266)}=.552, \mathrm{p}>.05\right]$ ,Telafi Edici Stratejiler $\left[\mathrm{F}_{(2-266)}=.984, \mathrm{p}>.05\right]$, Üstbilişsel Stratejiler $\left[\mathrm{F}_{(2-266)}=.365, \mathrm{p}>.05\right]$ ve 
Duyuşsal Stratejiler $\left[\mathrm{F}_{(2-266)}=2.418, \mathrm{p}>.05\right]$ alt boyutlarında anlamlı bir fark göstermezken, ölçeğinHafiza Stratejileri $\left[\mathrm{F}_{(2-266)}=3.308, \mathrm{p}>.05\right]$ ve Sosyal Stratejiler $\left[\mathrm{F}_{(2-266)}=3.078, \mathrm{p}>.05\right]$ boyutlarında anlamlı farklılık gösterdiği belirlenmiştir. Farkın hangi gruplar arasında olduğunu bulmak amacıyla Tukey HSD çoklu karşılaştırma analizi yapılmıştır.

Tablo 6.1.

Türkçeyi Yabancı Dil Olarak Öğrenenlerin Kullandıkları Dil Öğrenme Stratejilerinin Ana Dili Alfabe Değişkenine Göre ANOVA Sonuçlarının Betimsel Değerleri

\begin{tabular}{|c|c|c|c|c|}
\hline & & $\mathrm{N}$ & & SS \\
\hline & Latin alfabesi & 51 & 3.37 & .62 \\
\hline Hafiza & Arap alfabesi & 110 & 3.22 & .59 \\
\hline Stratejileri & Diğer & 108 & 3.09 & .67 \\
\hline & Toplam & 269 & 3.20 & .63 \\
\hline & Latin alfabesi & 51 & 3.81 & .75 \\
\hline Sosyal & Arap alfabesi & 110 & 3.50 & .72 \\
\hline Stratejiler & Diğer & 108 & 3.66 & .77 \\
\hline & Toplam & 269 & 3.62 & .75 \\
\hline
\end{tabular}

Farkın hangi gruplar arasında olduğunu belirlemek amacıyla yapılan Tukey HSD çoklu karşılaştırma testi sonucuna göre; Hafiza Stratejileri alt boyutunda ana dili alfabelerini Latin alfabesi olarak belirtenlerin dil öğrenme stratejilerini kullanma puan ortalamalarının $(\bar{X}=3.37)$, ana dili alfabelerini Arap alfabesi $(\bar{X}=3.22)$ ve Diğer $(X 3.09)$ olarak belirtenlere göre Türkçe öğrenirken kullandıkları dil öğrenme stratejileri puanlarının daha yüksek olduğu belirlenmiştir. Ölçeğin diğer bir alt boyutu olan Sosyal Stratejiler boyutunda da ana dili alfabelerini Latin alfabesi olarak belirtenlerin dil öğrenme stratejilerini kullanma puan ortalamalarının $(\bar{X}=3.81)$, ana dili alfabelerini Arap alfabesi ve Diğer $(\bar{X}=3.66)$ olarak belirtenlere $(\bar{X}=3.50)$ göre Türkçe öğrenirken kullandıkları dil öğrenme stratejileri puanlarının daha yüksek olduğu belirlenmiştir.

Yapılan analiz sonucunda Türkçeyi yabancı dil olarak öğrenenlerin kullandıkları dil öğrenme stratejileri ana dili alfabe değişkenine göre ölçeğin toplamında ise anlamlı farklılık göstermediği belirlenmiştir $\left[\mathrm{F}_{(2-266)}=1.36, \mathrm{p}>.05\right]$. Bu bulgular 1şı̆̆ında ana dili alfabesi olarak Latin alfabesi kullandığını belirtenlerin Türkçeyi öğrenirken dil öğrenme stratejilerini daha çok kullandığı söylenebilir.

\section{Sonuç ve Tartışma ve Öneriler}

Türkçeyi yabancı dil olarak öğrenenlerin kullandıkları dil öğrenme stratejilerini belirlemeyi amaçlayan bu çalışmada Türkçeyi yabancı dil olarak öğrenenlerin öğrenme stratejilerini sık sık düzeyinde kullandıkları belirlenmiştir. Wenden (1991) bazı dil öğrenenlerin diğerlerinden daha başarılı olduklarını çünkü nasıl öğrenmeleri gerektiğini bildiklerini belirtmektedir. Wenden'in sözlerine dayanarak araştırmaya katılan ve dil öğrenme stratejilerini sık sık ve ileri düzeyde kullanan öğrencilerin dil öğrenme stratejilerini kullanmayan öğrencilerden Türkçe öğrenirken daha başarılı olacağı söylenebilir.

Araştırmadan ortaya çıkan bu sonuç Ergin (2018) tarafından daha önce yapılan benzer çalışmanın sonucunun da Türkçeyi yabancı dil olarak öğrenenlerin dil öğrenme stratejileri ortalamalarının yüksek seviyede belirlenmesi yönüyle benzerlik gösterirken, Cesur (2008), Bölükbaş (2013), Barut (2015), Boylu (2015), tarafından yapılan benzer çalışmaların sonuçlarının orta seviyede tespit edilmesi yönüyle de farkl1l1k göstermektedir.

Yine bu araştırma sonucu Oxford (1990) tarafından geliştirilen ve Dil Öğrenme Stratejileri Envanteri kullanılarak Baş (2014) ve Mutlu (2018) tarafından Türkçe dışında farklı dilleri (İngilizce, Fransızca, Çince vb.) yabancı dil olarak öğrenenler ile çalışılmış araştırmaların sonuçlarında da bu araştırmada olduğu gibi öğrencilerin dil öğrenme stratejilerini kullanma ortalama puanlarının yükssek seviyede belirlenmesi yönüyle benzerlik göstermektedir. Fakat Yang 
(2010), Demirel (2012), Balcı ve Üğüten (2017), Çetinkaya (2017), Baysal (2018) tarafından farklı hedef kitlelere yapılan çalışmaların sonuçlarının dil öğrenme stratejilerini kullanma ortalama puanlarının orta seviyede çıkması yönüyle araştırmanın sonuçları farklılık göstermektedir.

Araştırma sonucunda Türkçeyi yabancı dil olarak öğrenen öğrencilerin sosyal stratejiler ile üstbilişsel stratejileri en yüksek seviyede kullandığı ve hafıza stratejilerini ise en düşük seviyede kullandıkları tespit edilmiştir. Bu araştırmadan elde edilen sosyal stratejiler ile ilgili sonuçlar alanyazında yapılan birçok çalışmanın sonuçlarıyla (Kılıç ve Padem, 2014; Nakatani, 2006; Thu, 2009; Wong, 2011) paralellik göstermektedir. Üstbilişsel stratejiler ile ilgili sonuçlar da Bölükbaş (2013) ile Boylu ve Özbay (2015) tarafından yapılan çalışmaların sonuçlarıyla örtüşürken Alptekin (2007), Deneme (2008), Razı (2012), Barut (2015), Varışoğlu (2017) tarafindan yapılan çalışmalarda alt boyutlardaki ortalama değerlerin telafi edici stratejilerde en yüksek seviyede tespit edilmesi yönüyle farkl1lık göstermektedir.

Hafıza stratejileriyle ilgili ulaşılan sonuçlar Demirel (2012) tarafından yapılan çalışmada da hafıza stratejilerinin en az kullanılan strateji olması yönüyle paralellik gösterirken, alanyazında yapılan diğer çalışmaların sonuçları (Alptekin, 2007; Barut, 2015; Boylu ve Özbay, 2015; Bölükbaş, 2013; Deneme, 2008; Hamamc1, 2012; Raz1, 2012; Varışoğlu, 2017; Y1lmaz, 2010) en az kullanılan stratejiyi duyuşsal stratejiler olarak belirlemesi yönüyle örtüşmemektedir. Alanyazında yapılan çalışmalardan bu çalışmanın farlılık göstermesi öğrencilerin duyuşsal stratejileri kullanma sıklı̆̆ının değiştiğini ve artık öğrencilerin dil öğrenme sürecinde inanç, tutum ve algılarını kontrol edebilecek stratejileri kullanma eğilimlerinin arttığını işaret etmektedir.

Araştırmadan elde edilen diğer bir sonuç da Türkçeyi yabancı dil olarak öğrenenlerin kullandıkları dil öğrenme stratejilerinin cinsiyet değişkeni açısından ölçeğin toplam boyutunda istatistiki olarak anlamlı bir ilişkiye sahip olmadığıdır. Araştırmanın toplam boyutundan elde edilen sonuca göre Türkçeyi yabancı dil olarak öğrenen öğrencilerin dil öğrenme stratejilerini kullanma puanlarını cinsiyet değişkenin etkilemediği belirlenmiştir. Sadece ölçeğin bilişsel stratejiler boyutunda kız öğrencilerin erkek öğrencilere oranla daha yüksek dil öğrenme stratejileri kullanma puanına sahip olduğu tespit edilmiştir. Karamanoğlu (2005) daha önce yaptığı araştırmasında Dil Öğrenme Stratejileri Envanterini Alman Dili eğitimi öğrencilerine uygulamış ve dil öğrenme stratejileriyle cinsiyet değişkeni arasında bir ilişki olmadığını belirlemesi yönüyle iki çalışmanın sonuçları birbiriyle örtüşmektedir. Yapılan bu araştırma alanyazında yapılan diğer çalışma sonuçlarının (Aslan, 2009; Barut, 2015; Baş, 2012; Bekleyen, 2005; Cesur, 2008; Kayaoğlu, 2011; Tok, 2007) k1z öğrenciler ve erkek öğrencilerin dil öğrenme stratejilerini kullanma puanlarının istatistiki olarak anlamlı çıkmasından dolayı farklılık göstermektedir. Yapılan çalışmada bilişsel stratejiler alt boyutuyla ilgili elde edilen sonuçlar daha önce yapılan çalışmalarda da (Bekleyen, 2005; Lee, 2003; Oxford ve Nyikos, 1989; Sheorey, 1999) bilişsel stratejiler alt boyutunda kız öğrencilerin erkek öğrencilere oranla dil öğrenme stratejilerini kullanma puanlarının daha yüksek seviyede belirlenmesi sonucuyla da örtüşmektedir.

Türkçeyi yabancı dil olarak öğrenenlerin kullandıkları dil öğrenme stratejileriyle Türk televizyon kanallarını izleme değişkeni arasındaki ilişki incelendiğinde ölçeğin toplam boyutu ile ölçeğin alt boyutlarından bilişsel ve üstbilişsel stratejiler boyutlarında istatistiki olarak anlamlılık oluşturduğu belirlenmiştir. Araştırmadan elde edilen bu bulgular sonucunda Türkçeyi yabancı dil olarak öğrenenlerin Türkçe yayın yapan televizyon kanallarını takip etmesinin dil öğrenme stratejilerinin kullanılma sıklığını olumlu yönde etkilediği söylenebilir. Ölçeğin bilişsel ve üstbilişsel stratejiler alt boyutlarında da istatistiki olarak bir anlamlılık görülmektedir. Dickinson (1995) öğrencilere özerk öğrenmenin öğretilmesi için özellikle bilişsel ve üstbilişsel stratejilerin farkına vardırılması ve etkin bir biçimde öğretilmesi gerektiğini vurgulamaktadır (Akt. Eren, 2015, s. 25). Araştırmanın alt boyutlarından ortaya çıkan sonuçlar Dickinson'nun sözlerini destekler niteliktedir. Demirezen (1990, s. 293) dil öğretiminde televizyon kanallarının izlenmesi gerekliliğini ve izlenmesinin önemini "Televizyon, video vb. gibi etmenlerin yabancı dil öğretimine katkısı yadsınamayacak bir gerçektir. Ayrıca sınıf ortamında öğretmenlerin bu etmenlere öğrencileri yönlendirmesinin dil öğretiminin kalitesini kısa bir sürede arttıracaktır" sözleriyle ifade etmektedir. Araştırmanın sonucu ve televizyon kanallarının dil öğrenimine 
katkısı, dil öğrenme stratejilerini olumlu yönde etkilemesi, yabancı dil öğretenlerin öğrenme ortamlarında öğrencileri Türkçe yayın yapan televizyon kanallarını izletmeye yönlendirmesinin gerekliliğine işaret etmektedir.

Araştırmadan elde edilen bir başka önemli sonuç da Türkçeyi yabancı dil olarak öğrenenlerin kullandıkları dil öğrenme stratejilerinin ana dili alfabe değişkenine göre ölçeğin toplamında anlamlı farklılık göstermezken, ölçeğin hafıza stratejileri ve sosyal stratejiler alt boyutlarında ise anlamlı farklılık gösterdiğinin tespit edilmesidir. Araştırma sonucunda Türkçeyi yabancı dil olarak öğrenenlerin ölçeğin hafıza stratejileri ile sosyal stratejiler alt boyutlarında ana dili alfabeleri Latin alfabesi olanların Arap alfabesi ve diğer alfabe olanlara göre dil öğrenme stratejilerini Türkçe öğrenirken daha fazla kullandığ ana dili alfabesi Latin alfabesi olanların Türkçeyi yabancı dil olarak öğrenirken dil öğrenme stratejilerini kullanmalarına olumlu katkı sağladığı söylenebilir.

Yine benzer örneklemlere aynı envanter kullanılarak Boylu (2015) tarafindan yapılan araştırmaya katılan öğrencilerin öğrenme stratejileri ile ana dilleri arasında toplam boyutta anlamlı bir ilişki olmadığı sadece hafıza stratejileri alt boyutunda anlamlı bir farklılık oluştuğu tespit edilmiştir. Benzer örneklemlere uygulanan araştırmada Türkçeyi yabancı dil olarak öğrenen öğrencilerin ana dilleriyle dil öğrenme stratejileri arasında bir fark oluşmayıp ana dili alfabe değişkeni ile farklılık oluşması dikkat çekmektedir. Bu sonuçlardan hareketle öğrencilerin dil öğrenme süreçlerinde öğrenme stratejilerini ana dili alfabelerinin etkilediği ve ana dili alfabeleri farklı olan öğrencilerin Türkçe öğrenirken daha çok zorlandığı bu duruma paralel olarak da dil öğrenme stratejilerini kullanmaya ihtiyaç duyduğu söylenebilir.

\section{Öneriler}

Yapılan bu araştırmaya dayanarak Türkçeyi yabancı dil olarak öğrenen öğrencilerin dil öğrenme stratejilerini kullanma düzeylerinin arttırılabilmesi için şu öneriler verilebilir;

- Öğrenim süreci içerisinde dil öğrenme stratejilerini kullanabilme becerisi öğrencilere kazandirılmalıdır.

- Öğrencilerin bireysel olarak daha iyi ikinci bir dili öğrenebilme becerisinin geliştirilmesi için bilişsel ve üstbilişsel stratejilerin kullanımı üzerine önemle durulmalıdır.

- Kı̈ öğrenciler gibi erkek öğrencilerin de Türkçenin yabancı dil olarak öğrenme sürecinde bilişsel stratejileri daha sık kullanması gerekmektedir. Bu nedenle erkek öğrenciler de bilişsel stratejilerin kullanımına teşvik edilmelidir.

- Türkçeyi yabancı dil olarak öğrenen öğrenciler ders öğretmenleri tarafından Türkçe yayın yapan televizyon kanallarını daha sık aralıklarla takip etmeye yönlendirilmelidir.

- Ana dili Latin alfabesi dışında olan öğrenciler Türkçe öğrenme sürecinde özel sınıflarda derslere alınmalı ve bu öğrencilere Türkçeyi öğrenmelerine yardımcı olacak öğrenme stratejilerine yönelik daha fazla etkinlikler verilerek dil öğrenme süreci kolaylaştırılmalıdır.

- Yapılan bu araştırma B1 ve B2 düzeyinde öğrenim gören öğrencilere uygulanmıştır. Farklı çalışmaların C1 ve C2 düzeyindeki öğrencilere de uygulanarak kıyaslamaların yapılmasının alan yazına yararı olacağı düşünülmektedir.

\section{Yayın etiği}

$\mathrm{Bu}$ araştırmada yayın etiğine dikkat edilmiştir. Araştırma, Mehmet Akif Ersoy Üniversitesi Girişimsel Olmayan Klinik Araştırmaları Etik Kurulu tarafından 03.04.2019 tarihinde 2019/4 numaralı toplantıda araştırmanın gerekçe, amaç, yaklaşım ve yöntemleri incelenmiş olup, GO 2019/81 Karar numarası ile etik açıdan uygun bulunmuştur.

Araştırmanın ekler kısmında etik kurul raporuna da yer verilmiştir.

\section{Kaynaklar}

Aksan, D. (1998). Her yönüyle dil ana çizgileriyle dilbilim. Ankara: TDK Yayınları. 
Altan, M. Z. (2003). Language learning strategies and foreign language achievement. Türk Ĕ̈itim Derneği Eğitim ve Bilim Dergisi, 129, 25-31.

Alptekin, C. (2007). Yabancı dil öğrenimde strateji seçimi: Doğal ve eğitsel dil edinimi. Eğitimde Kuram ve Uygulama, 31(1), 4-11.

Aslan, O. (2009). The role of gender and language learning strategies in learning english, (Unpublished Master's Thesis). The Graduate School of Social Sciences of Middle East Technical University, Ankara.

Aydin, T. (2003). Language learning strategies used by turkish high school students learning english (Yayımlanmamış yüksek lisans tezi). İstanbul Üniversitesi Sosyal Bilimler Enstitüsü, İstanbul.

Balcı, Ö. ve Üğüten, D. S. (2017). Üniversite hazırlık sınıfı öğrencilerinin kullandıkları dil öğrenme stratejileri. Journal of Turkish Language and Literature, 3(2), 41-54.

Barut, A. (2015). Yabancı dil olarak Türkçe öğrenen üniversite öğrencilerinin kullandıkları dil ögrenme stratejileri üzerine bir değerlendirme (Yayımlanmamış yüksek lisans tezi). İhsan Doğramacı Bilkent Üniversitesi Eğitim Bilimleri Enstitüsü, Ankara.

Baş, G. (2012). Öğrenme stratejileri öğretiminin öğrencilerin ingilizce dersindeki akademik başarılarına, tutumlarına ve biliş ötesi farkındalık düzeylerine etkisi. Kuramsal Eğitimbilim Dergisi, 5(1), 49-71.

Baş, G. (2014). Lise öğrencilerinin dil öğrenme stratejileri ile İngilizce dersindeki akademik başarıları arasındaki ilişki. Dokuz Eylül Üniversitesi Buca Eğitim Fakültesi Dergisi, $37,166-180$.

Baysal, S. (2018). Meslek yüksekokulu ögrencilerinin dil ögrenme stratejileri ile yabancı dile yönelik kalıplaşmış düşüncelerinin incelenmesi (Yayımlanmamış yükssek lisans tezi). Kahramanmaraş Sütçü İmam Üniversitesi Sosyal Bilimler Enstitüsü, Kahramanmaraş.

Bekleyen, N. (2005). Öğretmen Adayları Tarafından Kullanılan Dil Öğrenme Stratejileri. Çukurova Üniversitesi Sosyal Bilimler Enstitüsü Dergisi. 14(2),113-122.

Bekleyen, N. (2006). İngilizce öğretmen adaylarının dil öğrenme stratejileri kullanımı. Akdeniz Üniversitesi Türkçe Öğretim Merkezi Dil Dergisi, (132), 28-37.

Boylu, E. (2015). Yabancı dil olarak Türkçe öğrenenlerin dil öğrenme stratejilerini kullanma düzeyleri (Yayımlanmamış yüksek lisans tezi). Gazi Üniversitesi Eğitim Bilimleri Enstitüsü, Ankara.

Boylu, E. ve Özbay, M. (2015). Yabancı dil olarak Türkçe öğrenenlerin dil öğrenme stratejilerini kullanma düzeyleri. Route Educational and Social Science Journal, 2(3).

Bölükbaş, F. (2013). The effect of language learning strategies on learning vocabulary in teaching Turkish as a foreign language. Hacettepe Üniversitesi Eğitim Fakültesi Dergisi, 28(3), 55-68.

Cesur, M. O. ve Fer, S. (2007). Dil öğrenme stratejileri envanterinin geçerlik ve güvenirlik çalışması nedir? Yüzüncü Yıl Üniversitesi Eğitim Fakültesi Dergisi, 49-74.

Cesur, M. O. (2008). Üniversite hazırlı sınıfi ögrrencilerinin yabancı dil öğrenme stratejileri, ögrenme stili tercihi ve yabancı dil akademik başarısı arasındaki açıklayıcı ve yordayıcı ilişkiler örüntüsü (Doktora tezi). Yıldız Teknik Üniversitesi Sosyal Bilimler Enstitüsü, İstanbul.

Cesur, M. O. (2011). Dil öğrenme stratejileri, stilleri ve yabancı dilde okuma anlama başarısı arasındaki ilişkileri açıklayıcı bir model. Hacettepe Üniversitesi Eğitim Fakültesi Dergisi. 41, 83-93.

Çepni, S. (2007). Araştırma ve proje çalı̧̧malarına giriş. Trabzon: Celepler Matbaacılık.

Çetinkaya, G. (2017). The relationship among language learning strategies, motivation and academic achievement of untversty preparatory school students (Yayımlanmamış yüksek lisans tezi). Abant İzzet Baysal Üniversitesi Eğitim Bilimleri Enstitüsü, Bolu.

Demirel, M. (2012). Üniversite öğrencilerinin kullandıkları dil öğrenme stratejileri. Hacettepe Üniversitesi Ĕ̈itim Fakültesi Dergisi, 43, 141-153.

Demirezen, M. (1990). Video kullanımının yabancı dil öğrenimine getirdikleri. Hacettepe Üniversitesi Eğitim Fakültesi Dergisi, 5(5).293. 
Deneme, S. (2008). Language learning strategy preferences of turkish students. Journal of Language and Linguistic Studies, 4(2).

Ehrman, M. E. ve Oxford, R. L. (1990). Adult language learning styles and strategies in an intensive training setting. Modern Language Journal, 54(3), 311-327.

El-Dip, M. A. B. (2004). Language lerarning strategies in kuwait: links to gender, language level, and culture in a hybrid context. Foreign Language Annals, 7(1), 85-95.

Eren, İ. (2015). Ortaokul İngilizce ögretmenlerinin ögrencilerde ögrenen özerkliği geliştirmeye yönelik görüşlerinin incelenmesi (Yayımlanmamış yüksek lisans tezi). Kahramanmaraş Sütçü İmam Üniversitesi Sosyal Bilimler Enstitüsü, Kahramanmaraş.

Ergin, A. E. (2018). Tek dilli ve çok dilli ögrencilerin yabancı dil olarak Türkçe ögrenme stratejileri (Yayımlanmamış yüksek lisans tezi). Çanakkale Onsekiz Mart Üniversitesi Eğitim Bilimleri Enstitüsü, Çanakkale.

Ergin, M. (1999). Türk dil bilbigisi. Bayrak Basım, İstanbul, 3.

Gan, Z., Gillian, H. ve Liz, H. L. (2004). Understanding successful and unsuccesful efl students in chinese universities. The Modern Language Journal, 88(4), 229-244.

Göçer, A. (2009). Türkiye'de Türkçeyi yabancı dil olarak öğreten öğretmenlerin uygulamalarına yönelik nitel bir araştırma. Dil Dergisi,145, 28-47.

Hamamc1, Z. (2012). Üniversite hazırlık sınıfı öğrencilerinin dil öğrenme strateji tercihleri. Journal of Research in Education and Teaching, 1(3), 157-167.

Hancioglu, S. (2004). Vocabulary learning strategies employed by preparatory class students at adana anatolian teacher training high school (Yayımlanmamış yüksek lisans tezi). Çukurova Üniversitesi Sosyal Bilimler Enstitüsü, Adana.

Ian, R. ve Oxford. R. (2003). Language learning strategy profiles of elementary school students in taiwan. IRAL, International Review of Applied Linguistics in Language Teaching. 41(4), 331-372.

Kara, M. (2001). Learning strategies used in the development of two different aspects of foreign language proficiency: 'calp' in english and 'bics' in turkish (Yayımlanmamış Yüksek Lisans Tezi). Boğaziçi Üniversitesi Sosyal Bilimler Enstitüsü, İstanbul.

Karamanoglu, Ş. (2005). Almanca öğretmen adaylarında yabancı dil ögrenme stratejileri kullanımı (Yayımlanmamış yüksek lisans tezi). Uludağ Üniversitesi Sosyal Bilimler Enstitüsü, Bursa.

Karasar, N. (2012). Bilimsel araştırma yöntemi (23.baskı). Ankara: Nobel Yayıncılık.

Kayaoğlu, M. N. (2011). Language learning strategies: Theory, practice and issues. Germany: VDM, Verlang Dr. Müller.

Kılıç, A. ve Padem, S. (2014). Üniversite hazırlık sınıfı öğrencilerinin dil öğrenme stratejileri kullanımlarının çeşitli değişkenlere göre incelenmesi. Elementary Education Online, 13(2), 660-673.

Kızılaslan, İ. (2010). Yabancı dil öğretmen yetiştirme sürecinde kültürlerarasılık. Milli Ĕ̈itim, 185, 81-89.

Korkmaz, Z. (2007). Türkiye Türkçesi grameri-şekil bilgisi. Ankara: Türk Dil Kurumu Yayınları.

Lafford, B. (2004). The effect of the context of learning on the use of communication strategies by learners of spanish as a second languge learners. Studies In Second Language, 26(1), 201-225.

Lee, K. O. (2003). The relationship of school year, sex and proficiency on the use of language learning strategies in learning english of korean junior high school students. Asian EFL Journal.14.

Mcdonough, S. (2001). Promoting Self Regulation. Foreign Language Learners, 74(6), 323-326.

Mutlu, A. (2018). Dil ögrenme inanışlart ve dil ögrenme stratejileri: Ingilizce ögretmen adayları üzerine bir çalışma (Balıkesir Üniversitesi Örneği), (Yayımlanmamış yüksek lisans tezi). Balıkesir Üniversitesi Sosyal Bilimler Enstitüsü, Balıkesir.

Nakatani, Y. (2006). Developing an oral communication strategy inventory. The Modern Language Journal, 90, 151-168. 
Nisbet, D. L., Tindall, E. R. ve Arroyo, A. A. (2005). Language learning strategies and english proficiency of chinese üniversity students. Foreign Language Annals, 38(1), 100-107.

Oxford, R. L. ve Nyikos, M. (1989). Variables affecting choice of language learning strategies by university students. The Modern Language Journal, 73, 291-300.

Oxford, R. ve Crookal, D. (1989). Research on language learning strategies: methods, findings and instructional 1ssues. Modern Language Teaching, 41, 271-279.

Oxford, R. (1990). Language learning strategies: What everyone use. Boston Heinle and Heinle.

Oxford, R. L. (1999). Style wars' as a source of anxiety in language classrooms. D. J. Young (Yay. haz.). Affect in foreign language and second language learning, içinde (ss. 216237). Boston: Mac Graw- Hill.

Oxford, R., Cho, Y., Leung, S. ve Kim, H., J. (2004). Effect of the presence and difficulty of task on strategy use: an exploratory study. IRAL, International Review of Applied Linguistics in Language Teaching, 42(1), 1-47.

Ozil, Ş. (1991). Dil ve kültürümüz olgular ve sorunlar içinde. İstanbul: Cem Yayınevi.

Özdemir, E. (2000). Eleştirel okuma. Bilgi Yayın Evi, Ankara.

Razı, S. (2012). Turkish efl learners' language learning strategy employment at university level. Journal of Theory And Practice in Education, 8(1), 94-119.

Saussure, F. (1985). Genel dil bilim dersleri (B. Vardar, Çev.). Birey ve Toplum Yayınları.

Sheorey, R. (1999). An examination of language learning strategy use in the setting of an indigenized variety of english. System, 28(2), 173-190.

Smith, P. L. ve Ragan, T. J. (1999). Instructional design. New York: John Wiley Sons.

Tabanloglu, S. (2003). The relationship between learning styles and language learning strategies of pre-intermediate eap students (Yayımlanmamış yüksek lisans tezi). Orta Doğu Teknik Üniversitesi Sosyal Bilimler Enstitüsü, İstanbul.

Thu, T. H. (2009). Learning strategies used by successfull language learners. http://files.eric.ed.gov/fulltext/ED507398.pdf.

Varışoğlu, M. C. (2017). Türkçe öğrenen Litvanyalı öğrencilerin kullandıkları dil öğrenme stratejileri. Türkiyat Araştırmaları Enstitüsü Dergisi [Taed], 533- 546.

Weinstein, C. E., Humson, J. ve Dierking, D. R. (2000). Self- regulation invertions with a focus on learning strategies. M. Boekaerts, P. R. Pintrich ve M. Zeidner (Yay. haz.). Handbook of Regulation, içinde (ss.727-747). San Diegos Academic Pres.

Wenden, A. (1991). Learner strategies for learner autonomy. Cambridge: Prentice Hall International.

Wherton, G. (2000). Language learning strategy use of bilingual foreign language learners in Singapore. Languge Learning, 50(2), 203-243.

Wong, S. L. M. (2011). Language learning strategy use: A study of pre-service teachers in Malaysia, 1-21. Erişim adresi: http://eric.ed.gov/PDFS/ED521415.pdf

\section{Extended Abstract}

\section{Introduction}

people can communicate with other societies through language, even through established communication, societies can develop. The need for societies to communicate with each other in line with the evolving technology and needs is increasing every day. This situation revealed the necessity of learning a foreign language.

Özil (1991) the necessity of knowing the foreign language a foreign language or languages, and value systems of these languages introduced by the US perception of the world, and armed with the culture of that language, allowing to communicate better with people, both in developing our own thoughts and our own existence, which are the same between different cultures and beyond this, our own self-consciousness, we get better and it's better help identify our own position in the words is not explained. 
In parallel with this, the importance of knowing a foreign language has also increased since it is not a privilege to speak a foreign language and it is a quality that everyone should have (Göçer, 2009). With the increasing importance of speaking foreign languages, people turned to learning new languages other than their mother tongue. Like other languages, Turkish is one of the languages people want to learn as a foreign language. In parallel with this situation, the importance given to teaching Turkish as a foreign language is increasing day by day. According to Kizilaslan (2010), in order to ensure proper and effective communication between communities, foreign language speakers who focus more on cultural aspects than linguistic accuracy and who can look at cross-cultural differences with tolerance are needed.

The importance of teaching Turkish as a foreign language also increases the number of studies done on the field of teaching Turkish to foreigners. In line with the studies conducted, many factors affecting learners ' language learning process have been investigated and individual differences have been found to affect the language learning process.

It is observed that there is not much work done on the language learning strategies used by the students who learn Turkish as a foreign language when the field is scanned. The lack of enough work on this subject, which is very important for the language learning process, shows that there is a very important gap in the literature. In addition, it is thought that determining the language learning strategies used by the students who want to learn Turkish as a foreign language will positively affect the language learning process of the learners. Studies in literature and language learning strategies foreign language learners learning Turkish as a foreign language, this idea of a direct relationship between the determining aspect supports (Altan, 2003; Nisbet, Tindall \& Arroyo, 2005; Pending, 2006). The study carried out in this context is considered to be important in determining the language learning strategies used by learners of Turkish as a foreign language and to reveal the comparison with various variables.

This research is aimed at determining the language learning strategies used by learners of Turkish as a foreign language and whether the language learning strategies used by learners vary according to some variables.

The main problem of this research is "what are the language learning strategies used by those who learn Turkish as a foreign language?" it is designated as.

In this study, in addition to the basic sub-problem, answers to the following sub-problems were sought.

- At what level are the language learning strategies used by those who learn Turkish as a foreign language?

- Is there a relationship between the language learning strategies used by those who learn Turkish as a foreign language and the gender variable?

- Is there a relationship between the language learning strategies used by those who learn Turkish as a foreign language and the variable of watching Turkish television channels?

- Is there a relationship between the language learning strategies used by those who learn Turkish as a foreign language and the native language alphabet?

\section{Method}

"Descriptive screening model" was used in this research, which aims to identify language learning strategies used by learners of Turkish as a foreign language and to explain the relationship between these strategies with various variables. "The screening model is a research approach that aims to reveal a past or present situation as it exists" (Karasar, 2012, p. 77). In such studies, answers to the questions of what is the current situation of the event or problem and where are we (Çepni, 2007).

The universe of the research is composed of students studying at Turkish teaching Centers for foreigners in 2018-2019. The sample Mehmet Akif Ersoy University, Burdur, Süleyman Demirel University, Akdeniz University, Eskişehir Osman Gazi University, Gazi University Turkish to foreigners and university education centres, education and training undergoing 269 B1 
and B2 level students. The reason why students at B1 and B2 level are selected is that they are able to understand the questions on the scale.

In this study, "Language Learning Strategies inventory" and personal information form were used to determine the language learning strategies used by students who learn Turkish as a foreign language. Data in the study was analyzed through SPSS 21.00 and Lisrell programs. Since the inventory of language learning strategies is of the quintet likert type, the data is coded to increase from negative propositions to positive propositions. The 10 items in the personal information form are also defined in the SPSS 21.00 program.

\section{Result and Discussion}

This study aims to determine the language learning strategies used by learners of Turkish as a foreign language and it is determined that learners of Turkish as a foreign language use their learning strategies frequently. Wenden (1991) states that some language learners are more successful than others because they know how to learn. Based on Wenden's words, it can be said that the students who participated in the research and who used language learning strategies frequently and at an advanced level will be more successful in learning Turkish than the students who did not use language learning strategies.

This result from adult Survey (2018) by the results of previous similar studies also Turkish as a foreign language learners language learning strategies indicates a high level of similarity, determining an average of the aspect while Brave (2008), Bolukbas (2013), Gunpowder (2015), Tall (2015), to be determined by the results of similar studies at the intermediate level varies with the direction.

As a result of the research, it was determined that students who learn Turkish as a foreign language use social strategies and cognitive strategies at the highest level and use memory strategies at the lowest level. The results of social strategies obtained from this research are in parallel with the results of many studies in the field paper (Kılıç \& Padem, 2014; Nakatani, 2006; Thu, 2009; Wong, 2011).

Another result from the research is that the language learning strategies used by those who learn Turkish as a foreign language do not have a statistically significant relationship in the total size of the scale in terms of gender variables.

As a result of the findings obtained from the research, it can be said that the fact that those who learn Turkish as a foreign language follow the television channels broadcasting in Turkish positively affects the frequency of use of language learning strategies. In the lower dimensions of the Scale, Cognitive and transcendental strategies are also statistically significant. 